\title{
Gender Variation on the Perception of Climate Change Impact on Human Health in Moba Local Government Area of Ekiti State, Nigeria
}

\author{
Biola Badmos ${ }^{1, ~ *, ~ H e n r y ~ S a w y e r r ², ~ G a b r i e l ~ S a l a k o ~}{ }^{1}$, Atinuke Oyewumi ${ }^{2}$, Adeolu Adedotun ${ }^{2}$, \\ Oluwasogo Olalubi ${ }^{3}$, Olabisi Badmos ${ }^{4}$ \\ ${ }^{1}$ Department of Environmental Management and Toxicology, Kwara State University, Malete, Nigeria \\ ${ }^{2}$ Department of Environmental Health Science, Kwara State University, Malete, Nigeria \\ ${ }^{3}$ Department of Public Health, Kwara State University, Malete, Nigeria \\ ${ }^{4}$ Centre for Development Research, University of Bonn, Bonn, Germany
}

Email address:

biolakz@yahoo.com (B. Badmos), henry.sawyerr@kwasu.edu.ng (H. Sawyerr), gabsalako@yahoo.co.uk (G. Salako), oduntinuwumi89@gmail.com (A. Oyewumi), deetee4all@yahoo.com (A. Adeolu), olalubisogo@gmail.com (O. Olalubi), s7olbadm@uni-bonn.de (O. Badmos)

${ }^{*}$ Corresponding author

\section{To cite this article:}

Biola Badmos, Henry Sawyerr, Gabriel Salako, Atinuke Oyewumi, Adeolu Adeolu, Oluwasogo Olalubi, Olabisi Badmos. Gender Variation on the Perception of Climate Change Impact on Human Health in Moba Local Government Area of Ekiti State, Nigeria. Journal of Health and Environmental Research. Vol. 4, No. 1, 2018, pp. 1-9. doi: 10.11648/j.jher.20180401.11

Received: December 7, 2017; Accepted: December 26, 2017; Published: February 26, 2018

\begin{abstract}
This study investigated the influence of gender (sex) on the view of people towards the impact climate change on human health in south-west Nigeria. Data were collected by means of semi-structured questionnaire from impartial sampled males and females in Moba Local Government Area of Ekiti state, Nigeria. Using descriptive statistics and chi-square test, the collected data were analysed for (i) gender variation on the respondent's perception about climate change, (ii) gender variation in the perception of the respondents as regards the impact of climate change on human health, and (iii) association between sex type and perception on the impact of climate change on human health (malaria, disability, displacement, flooding, and cholera). Males and females showed comparable knowledge about climate change and its impact on human health, but males were slightly knowledgeable. In some aspect, gender showed significant association $(\mathrm{p} \leq 0.05)$ with respondent's view on the impact of climate change on human health. Females showed better awareness as regards climate change contributing to malaria, while males are better aware as regards climate change contributing to flooding. Important concern revealed in this study is the low public awareness on the indirect health impact of climate change. Hence, continuous enlightenment of people on the various health impacts of the changing climate is recommended.
\end{abstract}

Keywords: Climate Change, Perception, Health, Gender

\section{Introduction}

Climate change is a significant and rising threat to public health, particularly in the lower income populations and tropical/subtropical countries [1]. The change in the global climate has important and diverse impacts on human health $[2,3]$. It affects social and environmental determinants of health, such as clean air, safe drinking water, sufficient food and secure shelter $[4,5]$. Global warming may bring some localized benefits in certain areas, but the overall health effects are likely to be overwhelmingly negative [6], especially in least developed countries where vulnerability is highest [1]. There are three exposure pathways (Figure 1) through which climate change impact human health [7]. These include, (i) the direct pathways (primary pathways) are through extreme weather and climate events, such as heat and storms, (ii) the indirect pathways (secondary pathways) are through changes in natural systems that then affect disease vectors and disease transmission pathways, and (iii) the 
pathways mediated through human systems (tertiary pathways), such as under-nutrition. Climate change is already causing several thousands of deaths every year, through shifting patterns of disease, extreme weather events, such as heat-waves and floods, and from the degradation of air quality, food and water supplies, and sanitation [8]. Between 2030 and 2050, climate change is expected to cause approximately 250,000 additional deaths per year through malnutrition, malaria, diarrhea and heat stress [9]. The direct impacts of climate change may result in human injuries, illnesses and deaths related to extreme weather events and changes in weather patterns, rises in infectious diseases due to changes in vector-pathogen relations, and increased disease burdens from declines in water and air quality. Indirect impacts include impaired food security and nutrition as a result of changes in crop yields, as well as displacement and loss of livelihoods leading to negative health effects [10].

Climate change has contributed to the displacement of people [11, 12], there could be as many as 200 million people displaced by disruptions of monsoon systems and other rainfall regimes, droughts of unprecedented severity and duration, and by sea-level rise and coastal flooding [11]. In addition, coastal vulnerability also puts many people at risk for displacement [12]. A vast majority of the internal migrants (settler farmers) from the north-western part of Ghana who settled in a part of the southern Ghana (Brong Ahafo Region) mentioned environmental reasons for leaving their homes [13]. Excessive rainfall leading into extensive flooding has resulted into loss of lives and economic damage of billions of dollars $[14,15]$. The rise in the sea and ocean levels, as well as temperature and rainfall dynamics may increase the distribution of disease vectors such as dengue, malaria, pneumonia and incidence of diarrheal diseases, putting more people at risk [16]. Urban floods experienced by people can make them suffer mental disorders, spread diseases, destroy houses, assets and interrupt schooling. Harsh weather conditions in the northern part of Nigeria have been linked to different diseases [17].

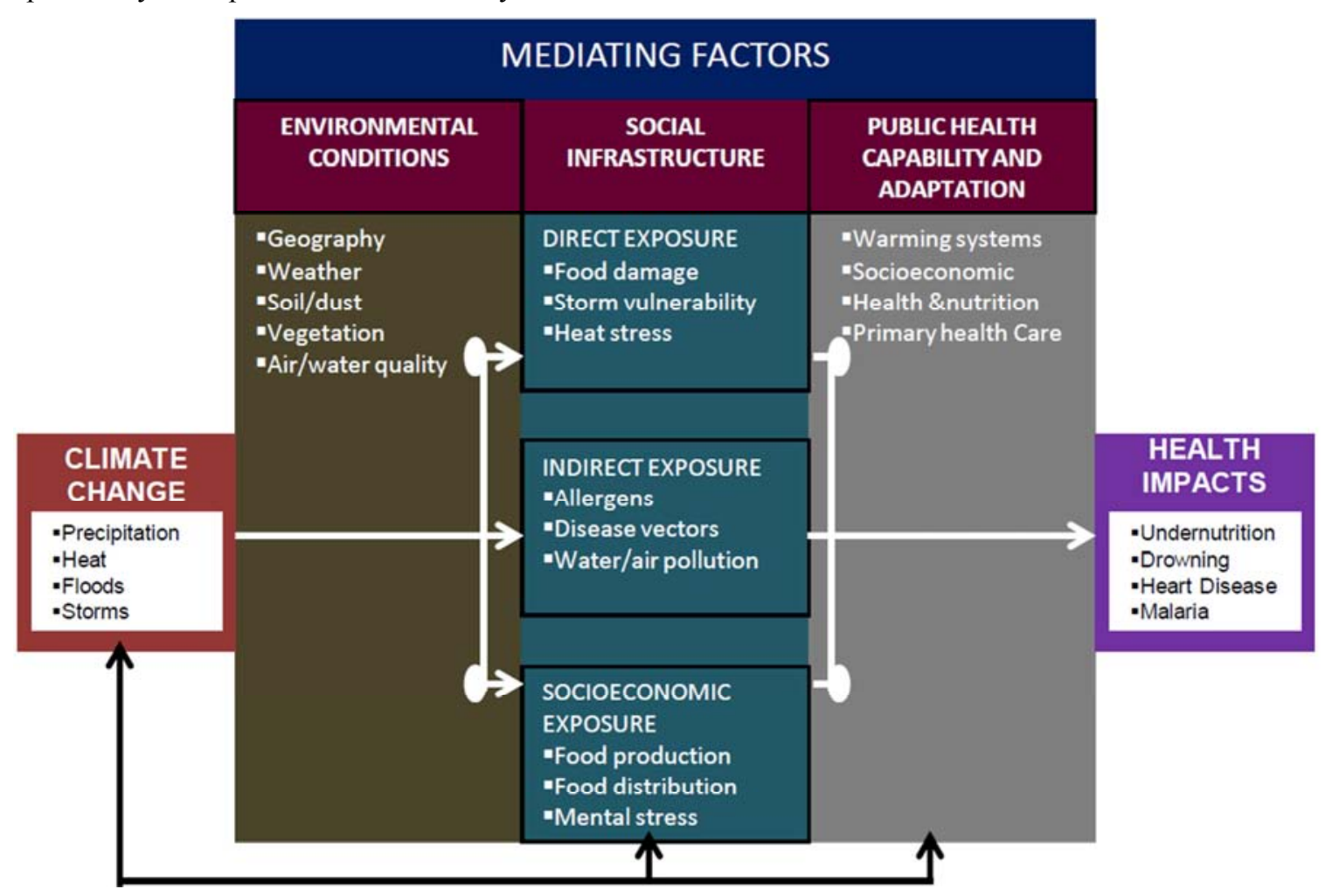

Figure 1. Exposure pathways by which climate change affects health [7].

Appropriate climate and weather conditions are necessary for the survival, reproduction, distribution and transmission of disease pathogens, vectors and hosts [18]. Therefore, changes in climate or weather conditions may impact infectious diseases through affecting the pathogens, vectors, hosts and their living environment [19, 20]. Long-term climate warming tends to favour the geographic expansion of several infectious diseases [21, 22, 23], and extreme weather events may create the opportunities for more clustered disease outbreaks or outbreaks at non-traditional places and time [24]. Although climate play vital role on human health, it also important to note that other non climatic factors also play a part. For instance, the socioeconomic status (e.g., access to health facility, poverty, education, occupation, income inequality, etc.) and development status are also fundamental determinants of certain health risk [25-29].

The relevance of gender in climate change studies have been shown in [30-34]. Gender element in climate change and adaptation looks at the different ways in which men and women contribute to climate change, the different impact that climate change has on men and women, the different ways that men and women respond to and are able to cope with 
climate change, and the differences in how they are able to shift from short term coping mechanisms to resilience [35]. According to [36], climate change impact is more likely to affect women than men as they spend most of their income on food purchases. Climate change will place additional burdens on women's health and have a triple effect on women because of their special physical vulnerabilities, their caring roles in families, and because the additional work which is required due to depletion of environmental conditions may lead to health damage [30]. The implication therefore is that there may be gender implication on how people perceive climate change and this can in turn influence their response. From human health point of view, this paper seeks to deepen knowledge on the gender implication of climate change perception. The following questions will be answered by this study: (i) what is the gender variation in the general perception climate change, (ii) what is the gender variation on how people perceive climate change impact on human health, (iii) Is there significant association between gender class and knowledge as regards the impact of climate change on selected human health parameters.

\section{Method}

\subsection{Study Area}

This study was conducted in Ekiti state, Nigeria, specifically in Moba Local Government Area - LGA (Figure 2). The state lies between latitudes $7^{\circ} 15^{1} \mathrm{~N}$ and $8^{\circ} 7^{1} \mathrm{~N}$ and longitudes $4^{\circ} 47^{1}$ $\mathrm{E}$ and $5^{\circ} 45^{1} \mathrm{E}$, and it is in the South-west Geo-political zone of Nigeria. It shares boundary with four states in Nigeria, two from North-central Geo-political zone (Kogi and Kwara state), and two from South-west Geo-political zone (Ondo and Osun state). The 2006 population census, which is the last census in Nigeria reported Ekiti state to cover a total land area of about $5,887.89 \mathrm{~km}^{2}, 16$ LGA and a population of about 2,398,957 [37]. The state lies within the equatorial climatic belt characterized by alternating tropical wet and dry seasons and classified as Koppen's Aw climatic type [38]. The state benefits from double maxima of rainfall. The rainy seasons usually commence from April to October while the dry seasons resume from late October/November to March with temperature ranges of between $21^{\circ} \mathrm{C}$ and $28^{\circ} \mathrm{C}$. The southern part of the state experience typical tropical rainforest while the guinea savanna forests are found towards the northern parts of the state [39]. Agriculture is the predominant occupation of the people, and their major produce includes cocoa, kola nut, orange (and other citrus), oil palm, maize, rice, cassava, yam and sweet potato. People also engage in trading and manufacturing of goods [40]. Moba LGA is located in the northern part of the state. Moba LGA covers a total land area of about $202.801 \mathrm{~km}^{2}$ and a population of about 145,408 $52.1 \%$ male and $47.9 \%$ female [37].

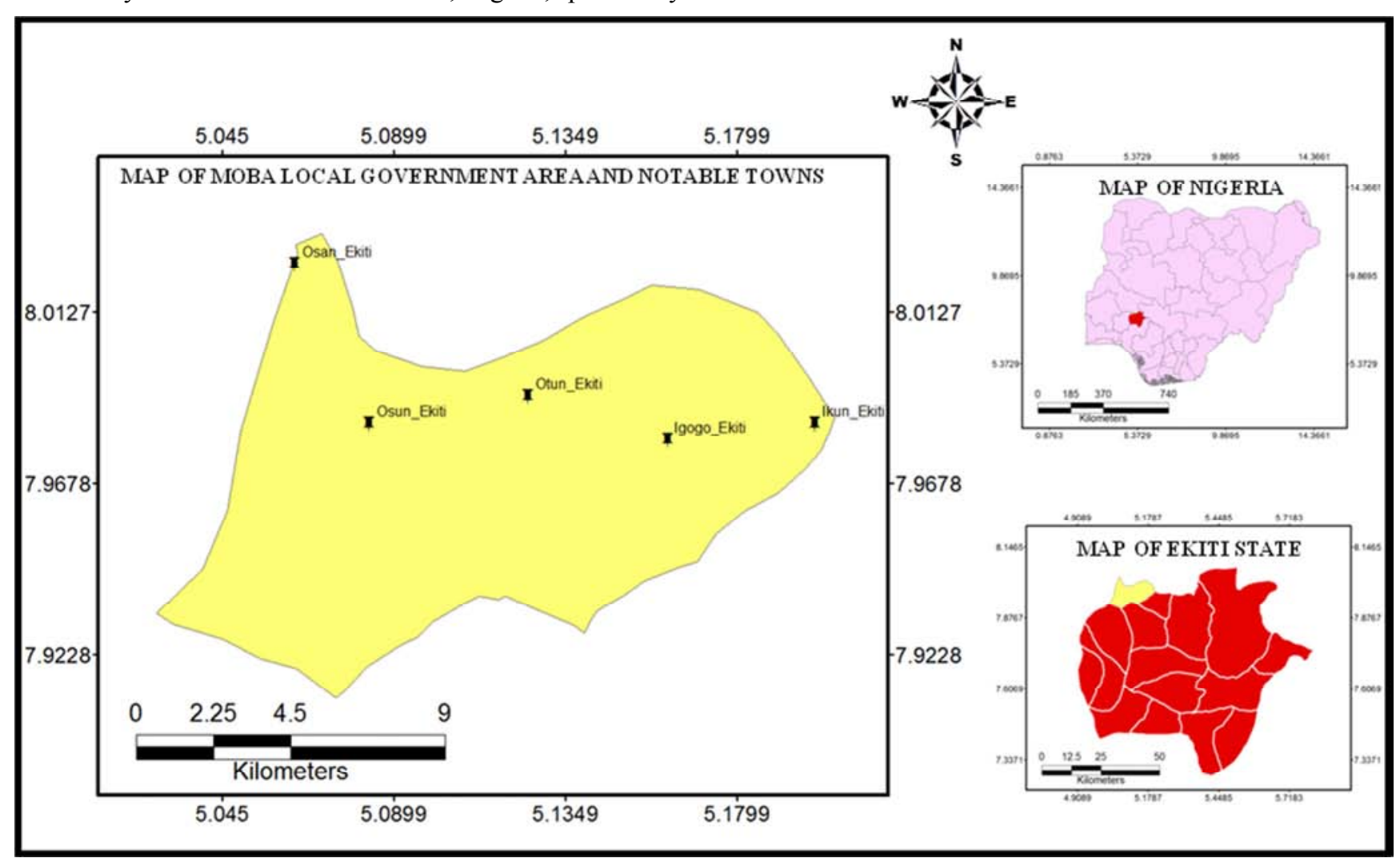

Figure 2. Map of the study area.

\subsection{Data Collection and Analysis}

This is a cross sectional study, and data were mainly collected through a semi structured questionnaire and oral interview. The questionnaires were administered between the period of September and October 2016. Sampling 
techniques involve purposive sampling and simple random sampling. Purposive sampling was used to select Moba LGA out of the 16 LGAs that make up Ekiti state. Due to resource constraint, a total of 200 questionnaires were distributed proportionately and randomly to the 13 communities in Moba LGA. In each community, proportionate number of males and females were selected as respondents. Literate respondents completed the questionnaires themselves, while those that could not read nor write were assisted by interpreting the questions to them. Ethical measures were ensured during the course of data collection. The participants were accorded the due respect so as to ensure co-operation. The information collected was treated with utmost confidentiality. Also, the cultures of each community were respected during the course of the field work. The quantitative data were analyzed in IBM-SPSS statistics software, version 20. The statistical method used includes descriptive statistics and Chi-square test (eq 1). The descriptive statistics was used to report the frequencies in tables and charts, while Chi-square test was used to test the association between gender type and their perception about the impact of climate change on human health. Open ended questions that looked at knowledge were assigned dimensions, such as weak, fair, good and very good knowledge. Respondent that did not provide relevant answers to the open ended questions that addressed knowledge were classified to have weak knowledge. Those that provide one, two three/ more than three relevant answers were classified to have fair, good and very good knowledge respectively.

$$
\mathrm{X}^{2}=\Sigma\left[\left(\mathrm{O}_{\mathrm{r}, \mathrm{c}}-\mathrm{E}_{\mathrm{r}, \mathrm{c}}\right)^{2} / \mathrm{E}_{\mathrm{r}, \mathrm{c}}\right]
$$

where, $\mathrm{X}^{2}=$ Chi-square; Or, $\mathrm{c}=$ Observed count at level $\mathrm{r}$ of variable A and level c of Variable B; Er, c = Expected count at level $r$ of Variable A and level c of Variable B.

\section{Results}

\subsection{Characteristics of the Respondents}

The socio-demographic characteristic of the respondents is shown in table 1 . About $47.2 \%$ of the respondents were females, while $52.8 \%$ were males. In both sexes, more of the respondents fall within the age bracket of $31-40$ years, while the least number fall in the age bracket of $41-50$ years. The marital status (single or married) showed a proportionate distribution across the sexes. Almost equal numbers of the two sexes have received formal education (Female - 85\%; Male - 84.6\%). Moreover, more females have tertiary education qualification $(62.4 \%)$ compared to males $(59.6 \%)$, while more males $(17.3 \%)$ possess secondary education qualification compared to females $(11.8 \%)$. The main occupation categories of the respondents are farming, civil servant, artisan, trading and student. Larger numbers of females $(30.1 \%)$ are employed as civil servants, while larger numbers of males $(35.6 \%)$ are employed in the farming job.

Table 1. Socio-demographic characteristic of the respondents.

\begin{tabular}{llll}
\hline & Level & Female (\%) & Male (\%) \\
\hline \multirow{4}{*}{ Age } & $20-30$ & 31.1 & 26.9 \\
& $31-40$ & 36.6 & 29.8 \\
Marital status & $41-50$ & 22.6 & 26.9 \\
& Above 50 & 9.7 & 16.4 \\
& Single & 33.3 & 35.6 \\
Education & Married & 66.7 & 64.4 \\
& Primary & 10.8 & 7.7 \\
& Secondary & 11.8 & 17.3 \\
& Tertiary & 62.4 & 59.6 \\
& None & 15.0 & 15.4 \\
& Farming & 10.8 & 35.6 \\
& Civil servant & 30.1 & 18.3 \\
& Artisan & 15.1 & 6.7 \\
& Student & 15.1 & 20.2 \\
& Trading & 16.1 & 3.8 \\
& Others & 12.8 & 15.4 \\
\hline
\end{tabular}

\subsection{Gender Variation on the General Knowledge About Climate Change}

This objective looked at gender variation in the general perception and knowledge of respondent concerning climate change. This objective was addressed by knowing the view of respondent as regards the observed changes in the weather pattern, information received about climate change and the source (s) of information. Also addressed is their knowledge on the factors contributing to climate change, as well their knowledge on the remedy to climate change issue.

More males (95.2\%) compared to females (89.2\%) perceived observable change in the weather pattern (Figure 3a). Majority of the respondents have received information about climate change, but most from a single source. Greater number of the respondents that received information from more than one sources are males (Figure $3 b$ ). More males $(85.6 \%)$ compared to females $(73.1 \%)$ considered climate change to be a critical issue that requires urgent attention (Figure 3c). From the stand point of personal importance attached to climate change (Figure $3 \mathrm{~d}$ ), majority of the respondents considered climate to be important personally, though more of the males than the females. An appreciable number of people did not see climate change issue to be of personal importance to them. Going further, more males agreed that climate change issue can be resolved (Figure 3e). Majority of the respondents (more males than females) have better knowledge on the factors contributing to climate change (Figure 3f). It is interesting to note that, a good number of the respondents (more females than males) have weak knowledge on the factors contributing to climate change. 

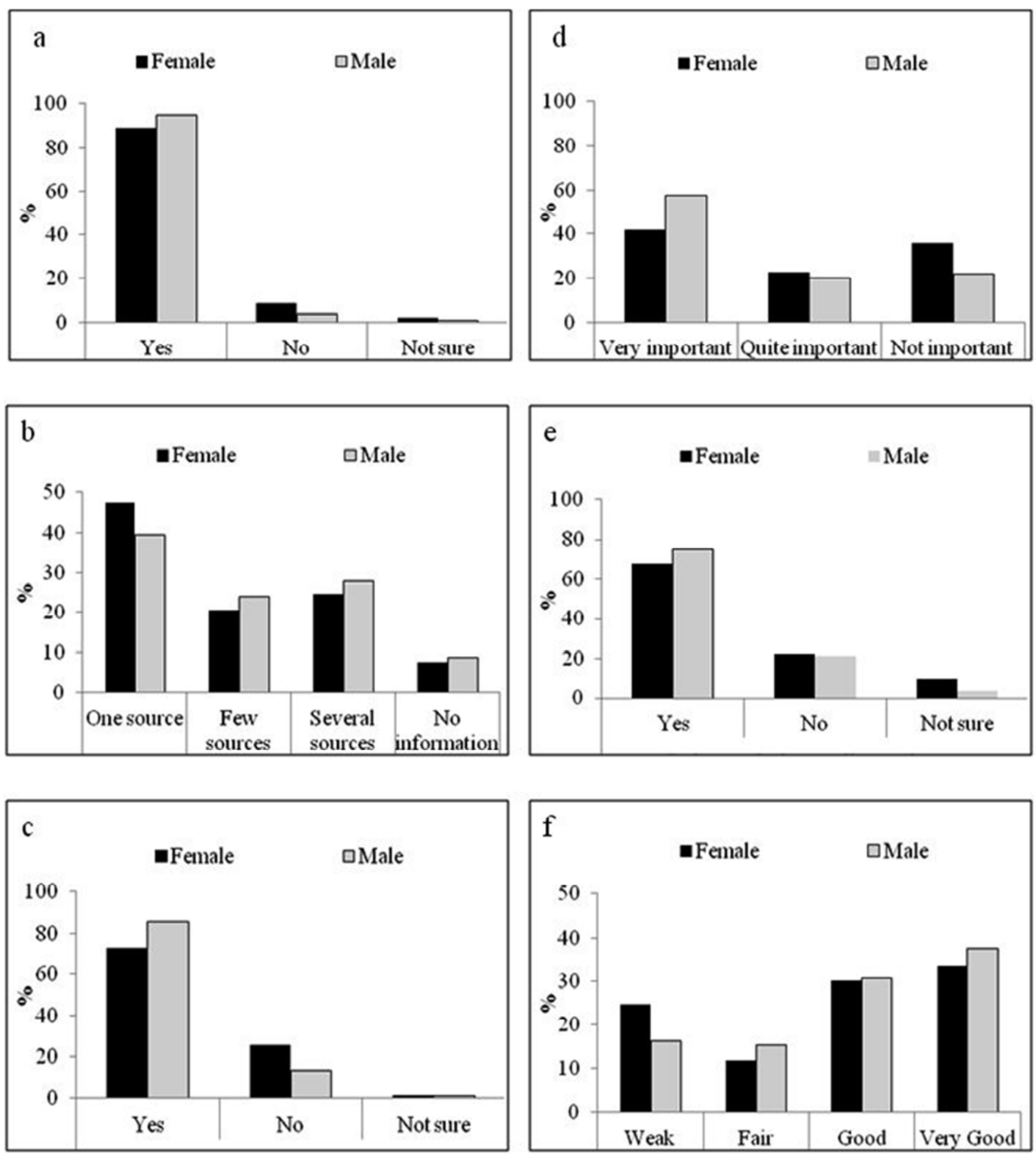

Figure 3. (a) Observable change in weather, (b) Sources of information about climate change, (c) Perception of climate change as an issue that needs immediate attention, (d) Level of personal importance attached to climate change issue, (e) Perception on whether there is solution to climate change, (f) Knowledge on the drivers of climate change.

\subsection{Gender Variation on the Perception of Climate Change Impact on Human Health}

This objective assessed the perception and knowledge of males and females regarding the impact of climate change on human health. The knowledge of the respondents regarding the relationship between climate change and general human health was assessed. Also considered is the availability of information to people as regards the impact of climate change on human health. Further, comparison was made regarding the variation in the view of males and females on climate change a as contributor to selected human health parameters.

There is almost a proportionate pattern in the number of females and males that have received information about the impact of climate change on human health (Figure 4a). Majority obtained their information from a single source. It is important to note that a very good number of the respondent (Male - 23.1; Female - 24.7) have not received information 
on the impact of climate change on human health. Considering the perceived impact of climate change on human health (Figure 4b), majority of the respondents from both sexes believed that climate change has negative impact on human health, with more males $(78.8 \%)$ than the females $(66 \%)$. In the case of selected human health parameters

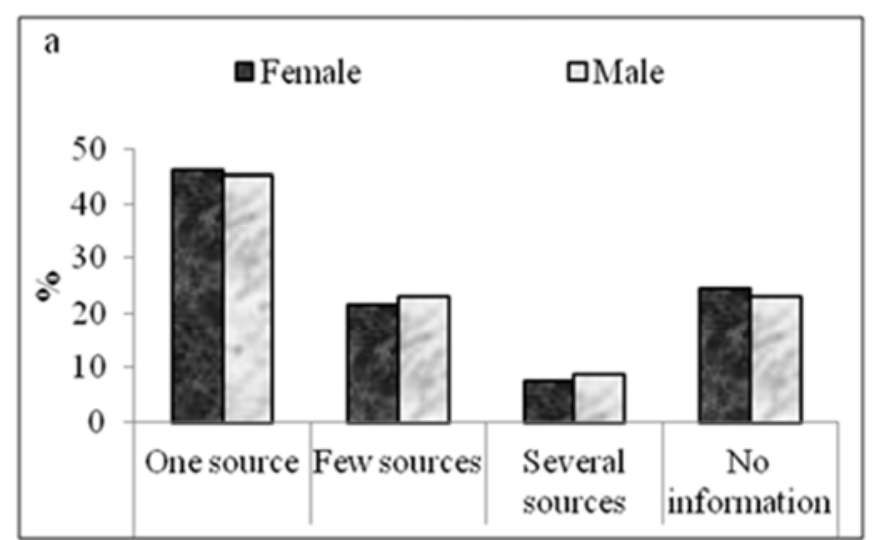

Figure 4. (a) Source of information on the impact of climate change on human health, (b) Perceived impact of climate change on human health.

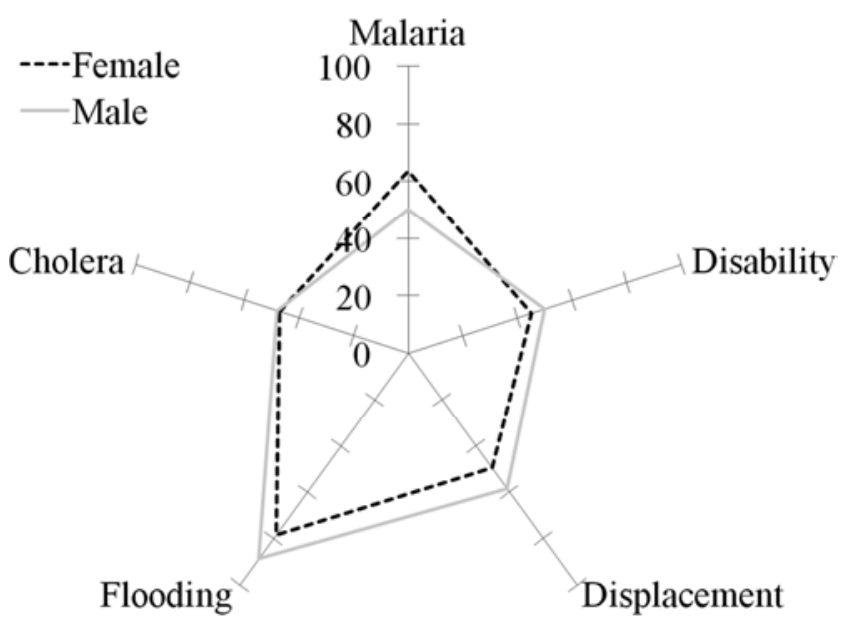

Figure 5. Respondents' agreement (\%) to the impact of climate on human health parameters.

\subsection{Association Between Gender Class and the Impact of Climate Change on Selected Human Health Parameters}

The association between gender type and perception about climate change as contributor to selected human health parameters is summarised in table 2. Among the five health parameters tested, significant association ( $\mathrm{p} \leq$ 0.05 ) was observed between sex type and their perception as regards climate change contributing to malaria $(\mathrm{p}=$ $0.049)$ and flooding $(p=0.045)$. Females have significant positive perception relationship with malaria. This implies that females have more likelihood of considering malaria as an implication of climate change. In the case of flooding, males have significant positive perception relationship with flooding. This implies that males are more likely to consider flooding as an implication of climate change.

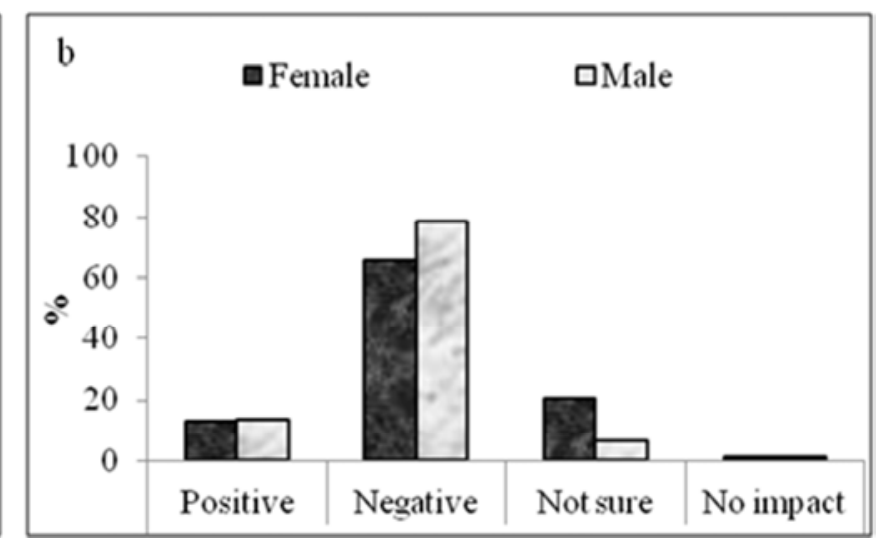

(malaria, disability, displacement, flooding, and cholera), more females compared to males agreed that climate change can contribute to malaria. However, the reverse is the case for disability, displacement, flooding and cholera where more males agreed that climate change is a contributor (Figure 5).

Table 2. Gender type and perception about climate change as contributor to selected human health parameters.

\begin{tabular}{lll}
\hline Health parameter & Chi square & P-Value \\
\hline Malaria & 3.87 & $0.049^{* *}(\mathrm{f})$ \\
Disability & 0.42 & 0.516 \\
Displacement & 1.25 & 0.264 \\
Flooding & 4.00 & $0.045^{* *}(\mathrm{~m})$ \\
Cholera & 0.04 & 0.844 \\
\hline
\end{tabular}

$(* *)=\mathrm{p} \leq 0.05 ;(\mathrm{f})=$ Female having higher likelihood; $(\mathrm{m})=$ Male having higher likelihood.

\section{Discussion}

A high level of awareness on the links between climate change and human health may help to increase the success of the National Prevention Program on Climate Change [41]. Moreover, understanding the concerns of the people may help policy makers develop and implement effective and sustainable adaptation measures. This study revealed that sex type played certain role on how people perceive climate change and its impact. Generally, both sexes considered that there have been observable changes in the weather pattern in the recent time. Access to information can increase people's awareness and knowledge, especially in the case of changing climate. How often one hear about an event and sources of such information may influence ones response. The respondents have received information about climate change, but the sources and the number of source varies according to sex. More male respondents have received information about climate and they have received information about climate change from multiples sources as compared to females. More males compared to females considered climate change to be a critical issue that requires urgent attention. Also, the number of people that attached personal importance to climate change issue is more for the males than females.

Information drives knowledge, attaching importance to 
climate change issue may be linked to the quality and amount of information received. There is a significant positive relationship ( $\mathrm{p} \leq 0.05)$ between how respondents considered climate change as a critical issue, the personal importance attached to climate change and the sources of information about climate change. It is important to note that a good number of the female respondents did not consider climate change issue to be of personal importance. This could be linked to the fact that there is variation in the source of livelihood and the sensitivity of each source across each gender class. For instance more of the males respondents $(35.6 \%)$ are farmers compared to $10.8 \%$ in the females. Furthermore, larger numbers of female respondents in this study are into less climate risky occupation, such as civil servants, artisans and trading. A similar pattern was observed in the case of respondent's knowledge on the drivers of climate change. Majority of those with weak knowledge as regards the factors contributing to climate change are females. A significant positive correlation $(p \leq 0.05)$ was also observed between sources of information about climate change and respondents knowledge about the drivers of climate change, and respondents' opinion of whether there is remedy to climate change issue

The variation on how the impact of climate change is perceived on human health across the gender types shows similar pattern as the way climate change is perceived generally. More of the male respondents perceived that climate change is connected to human health and that more of the impacts of climate change on health are negative. In the same way, more male respondents have received information about climate change from multiples sources as compared to the females. Importantly, some patterns were observed. In terms of general knowledge about climate change, a good number of the respondents received information about climate change from single to several sources (Female - 92.5\%; Male - 91.3\%). However, in case of information about the impact of climate change on human health, the number of respondents that have received information reduced conspicuously (Female - 75.3\%; Male $76.9 \%$ ). Across both sexes, there was never a situation where vast majority of the respondents considered climate change as a driver of the selected health parameters, except for flooding which is a direct impact of climate change. This also agree with the findings of a study in Ethiopia where flooding was identified as the main impact of climate change [42]. This is an important concern in climate change policy because weak awareness on the impact of climate change will have effect on how people will respond. It is therefore important create consciousness in people on the relationship between climate change and specific human health parameters, especially the indirect health impacts.

Looking at the association between gender class and the impact of climate change on selected human health parameters, males have perceived climate change and its impact on human health than females. This agrees with a finding of in Vietnam, where men were almost 1.6 times more likely to have heard of the impacts of climate change than women [41]. Similarly, in Kyuso District of the Eastern province of Kenya, there was a higher probability that male headed household would perceive climate change better than a female headed household [43]. This was attached to the facts that male headed households have a higher probability of acquiring information than female headed households. This also agrees with this study where more males had access to climate change information better than females. In [42], a slightly higher proportion of females compare to males were aware of climate change and its health impacts. The caring roles of women have made climate change to place additional burdens on women's health [30]. This might explain the pattern observed in this study where female respondents associated malaria to climate change better than males, because females might be responsible for taking care of household member affected by disease.

\section{Conclusion}

This study investigated the role of gender on the perception of people about the impact of climate change on human health in Moba Local Government Area of Ekiti state Nigeria. Data was collected by means of semi structured questionnaire. The questionnaires addressed respondents' general climate change knowledge and their specific knowledge about the impact of climate change on human health. The data were categorised based on sexes and they were subjected to descriptive statistics and chi square analysis. From the general perspective, both sexes have good knowledge of climate change, both males appears to be slightly knowledgeable. The specific knowledge of both sexes as regards the impact of climate change on human health showed similar pattern as the general knowledge. Females are better aware that climate change can be a driver for malaria, while males are better aware that climate change can be a driver for flooding. This study reveals that the gap in climate change knowledge between male and females is closing up. The implication therefore is that across sexes, people can prepare and respond uniformly towards the impact of climate change. However, important concern revealed in this study is the low public awareness on the indirect health impact of climate change. Hence, the need to continuously enlighten people on the direct and indirect health impacts of the changing climate.

\section{Acknowledgements}

Authors will like to appreciate the field assistants for their time on the field.

\section{References}

[1] IPCC - Intergovernmental Panel on Climate Change. (2001), Climate change-impacts, adaptation, and vulnerability, Third assessment report of the Intergovernmental Panel on Climate Change. Cambridge University Press, Cambridge, United Kingdom and New York, NY, USA. 
[2] McMichael, A. J. and Lindgren, E. (2011), "Climate change: present and future risks to health, and necessary responses", Journal of Internal Medicine, Vol. 270, No. 5, pp. 401-413.

[3] Woodward, A., Hales, S., Litidamu, N., Phillips, D. and Martin, J. (2000), "Protecting human health in a changing world: the role of social and economic development", Bulletin of the World Health Organization, Vol. 78, No. 9, pp. 11481155 .

[4] Arnell, N. W. (2004), Climate change and global water resources: SRES emissions and socio-economic scenarios. Global Environmental Change, Vol. 14, No. 1, pp 31-52.

[5] IPCC. (2007), Climate Change-Impacts, Adaptation and Vulnerability, Fourth Assessment Report of the Intergovernmental Panel on Climate Change. Cambridge University Press, Cambridge, United Kingdom and New York, NY, USA

[6] Mansour, S. A. (2013), "Impact of Climate Change on Air and Water Borne Diseases", Air and Water Borne Diseases, Volume 3, e126.

[7] IPCC. (2014), Climate Change-Impacts, Adaptation and Vulnerability, Fifth assessment report of the Intergovernmental Panel on Climate Change. Cambridge University Press, Cambridge, United Kingdom and New York, NY, USA

[8] WHO (2015), WHO calls on countries to protect health from climate change, available at:

http://www.who.int/mediacentre/news/statements/2015/climat e-change/en/, (accessed 25 January 2017).

[9] WHO - World Health Organisation (2014), Quantitative risk assessment of the effects of climate change on selected causes of death, 2030s and 2050s. World Health Organization, Geneva.

[10] Akerlof, K. L., Delamater, P. L. Boules, C. R. Upperman., C. R. and Mitchell, C. S. (2015), "Vulnerable Populations Perceive Their Health as at Risk from Climate Change", International Journal of Environmental Research and Public Health, Vol. 12, No. 12 pp. 15419-15433.

[11] Myers, N. (2005), "Environmental Refugees: An emergent security issue', paper presented at the 13th Economic Forum, 23-27 May 2005, Prague, available at: www.osce.org/documents/eea/2005/05/14488_en.pdf.

[12] Myers, S. S. and Bernstein, A. (2011), "The coming health crisis: indirect health effects of global climate change", F1000 Biology Report, Vol. 3, No. 3, pp. 1-5.

[13] Van Der Geest, K. (2004), We're Managing!: Climate Change and Livelihood Vulnerability in Northwest Ghana (Vol. 74). Leiden: African Studies Centre.

[14] Jonkman, S. (2005), Global perspectives on loss of human life caused by floods. Natural. Hazards, Vol. 34, No. 2, pp. 151175.

[15] Grossi, P. and Muir-Wood, R. (2006), The 1906 San Francisco earthquake and fire: Perspectives on a modern super cat. RMS, Incorporated, available at: http://forms2.rms.com/rs/729-DJX565/images/eq_1906_san_francisco_eq.pdf (accessed 25 January 2017).

[16] Haines, A., Kovats, R. S. D., Campbell-Lendrumb, C. and
Corvalan, C. (2006), "Climate Change and Human Health: Impacts, Vulnerability and Public Health", Public Health, Vol. 120 , No. 7 , pp. $585-596$.

[17] Tunde, A. M., Adeleke, E. A. and Adeniyi, E. E. (2013), "Impact of climate variability on human health in Ilorin, Nigeria", Environment and Natural Resources Research, Vol. 3, No. 1, pp. 127-134.

[18] Wu, X., Lu, Y., Zhou, S., Chen, L. and Xu, B. (2016), "Impact of climate change on human infectious diseases: Empirical evidence and human adaptation". Environment international, Vol. 86, pp. 14-23.

[19] Epstein, P. R. (2001), "Climate change and emerging infectious diseases", Microbe and Infection, Vol. 3, No. 9, pp. 747-754.

[20] Wu, X., Tian, H., Zhou, S., Chen, L. and Xu, B. (2014), "Impact of global change on transmission of human infectious diseases", Science China Earth Sciences, Vol. 57, No. 2, pp. 189-203.

[21] Epstein, P. R., Diaz, H. F., Elias. S. and Grabherr, G. (1998), "Biological and physical signs of climate change: focus on mosquito-borne diseases", Bulletin of American Meteorological Society, Vol. 79, No. 3, pp. 409-417.

[22] Ostfeld, R. S. and Brunner, J. L. (2015), "Climate change and Ixodes tick-borne diseases of humans", Philosophical Transactions of the Rpyal Society B, Vol. 370, No. 1665.

[23] Rodo, X., et al. (2013), "Climate change and infectious diseases: Can we meet the needs for better prediction?", Climatic Change, Vol. 118, No. 3-4, pp. 625-640.

[24] Epstein, P. R. (2000), "Is global warming harmful to health?:' Scientific American,. Vol. 283, No. 2, pp. 50-57.

[25] Stoltzfus, J. D., et al. (2014), "Interaction between climatic, environmental, and demographic factors on cholera outbreaks in Kenya", Infectious Diseases of Poverty, Vol. 3, No. 37, pp. 1-10.

[26] Olago, D., et al. (2007), "Climatic, socio-economic, and health factors affecting human vulnerability to cholera in the Lake Victoria basin, East Africa:, Ambio., Vol. 36, No. 4, pp. 350358 .

[27] Hurt, L. S., Ronsmans, C., and Saha, S. (2004), "Effects of education and other socioeconomic factors on middle age mortality in rural Bangladesh", Journal of Epidemiology and Community Health, Vol. 58, No. 4, pp. 315-320.

[28] Moss, N. E. (2002), "Gender equity and socioeconomic inequality: a framework for the patterning of women's health", Social Science and Medicine, Vol. 54, No. 5, pp. 649-661.

[29] Farmer, P. E., Nizeye. B., Stulac, S. and Keshavjee, S. (2006), "Structural violence and clinical medicine", PLoS Medicine, Vol. 3, No. 10.

[30] Roehr U. (2007), "Gender, climate change and adaptation: Introduction to the gender dimensions. Background paper prepared for Both Ends briefing paper Adapting to climate change: How local experiences can shape the debate", Berlin, Genanet, August 2007.

[31] Ajani, E. N., Onwubuya, E. A. and Mgbenka, R. N. (2013), "Approaches to economic empowerment of rural women for climate change mitigation and adaptation: Implications for policy", Journal of Agricultural Extension, Vol. 17, No. 1, pp. 23-34 
[32] Villamor, G. B., Desrianti, F., Akiefnawati, R., Amaruzaman, S. and van Noordwijk, M. (2014). Gender influences decisions to change land use practices in the tropical forest margins of Jambi, Indonesia. Mitigation and Adaptation Strategies for Global Change, Vol. 19, No. 6, pp. 733-755.

[33] Falaki, A. A., Akangbe, J. A. and Ayinde, O. E. (2013), "Analysis of Climate Change and Rural Farmers' Perception in North Central Nigeria", Journal of Human Ecology, Vol. 43, No. 2, pp. 133-140.

[34] Oloukoi, G., Fasona, M., Olorunfemi, F., Adedayo, V., and Elias, P. (2014), "A gender analysis of perceived climate change trends and ecosystems-based adaptation in the Nigerian wooded savannah", Agenda, Vol. 28, No. 3, pp. 16-33.

[35] Annecke, W. (nd.), "Adaptation and beyond - Gender and Climate change adaptation", available at: www.r4d.dfid.gov.uk/PDF/Outputs/ClimateChange/Adaptatio nandbeyond04small.pdf (accessed 02 January 2015).

[36] Makhura, M. T. (2001), "Overcoming transaction costs barriers to market participation of smallholder farmers in Limpopo province of South Africa", PhD Thesis, University of Pretoria.

[37] NPC - National Population Commission. (2010), Priority table volume iii: Population distribution by sex, state, LGA and Senatorial district. National Population Commission of Nigeria.
[38] Ojo, O. (1980), Climate of Africa. Heinemam, Ibadan.

[39] Ayeni, G. O. and Afolabi, F. I. O. (2008), "The application of Geographic Information Systems to the spatial distribution of Poverty in Ekiti state, Nigeria", International Journal of Education and Research, Vol. 4, No. 7, pp. 125-136.

[40] Oyesola, O. B. and Obabire, I. E. (2011), "Farmers' perceptions of organic farming in selected local government areas of Ekiti State, Nigeria", Journal of Organic Systems, Vol. 6, No. 1, pp. 20-26.

[41] Toan, D. T. T., Kien, V. D., Giang, K. B., Minh, H. V. and Wright, P. (2014), "Perceptions of climate change and its impact on human health: an integrated quantitative and qualitative approach", Global Health Action, Vol 7.

[42] Nigatu, A. S., Asamoah. B. O. and Kloos, H. (2014), "Knowledge and perceptions about the health impact of climate change among health sciences students in Ethiopia: a cross-sectional study", BMC Public Health Vol. 14, No. 587, pp. 1-10.

[43] Ndambiri, H. K., Mbogoh. S. G. and Ritho, C. N. (2013), “An evaluation of farmers' perceptions of and adaptation to the effects of climate change in Kenya", International Journal of Food and Agricultural Economics, Vol. 1, No. 1, pp. 75-96. 